\title{
A pegada ideológica na narrativa da segunda revolução académica. Análise crítica da construção de um paradigma
}

The Ideological Footprint on the Narrative of the Second Academic Revolution. A Critical Analysis of the Construction of a Paradigm

La trace idéologique dans la narrative de la seconde révolution académique.

Analyse critique de la construction d'un paradigme

\section{Rosário Couto Costa}

\section{OpenEdition}

Journals

Edição electrónica

URL: https://journals.openedition.org/rccs/7205

DOI: $10.4000 /$ rccs.7205

ISSN: 2182-7435

\section{Editora}

Centro de Estudos Sociais da Universidade de Coimbra

Edição impressa

Data de publição: 1 setembro 2018

Paginação: 49-70

ISSN: 0254-1106

Refêrencia eletrónica

Rosário Couto Costa, «A pegada ideológica na narrativa da segunda revolução académica. Análise crítica da construção de um paradigma», Revista Crítica de Ciências Sociais [Online], 116 | 2018, publicado a 31 julho 2018, consultado a 21 setembro 2021. URL: http://journals.openedition.org/rccs/ 7205 ; DOI: https://doi.org/10.4000/rccs.7205

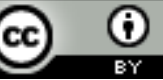




\section{ROSÁRIO COUTO COSTA}

\section{A pegada ideológica na narrativa da segunda revolução académica. Análise crítica da construção de um paradigma*}

Neste artigo faz-se uma revisão crítica da segunda revolução académica. O objetivo é mostrar como esse marco é passível de diferentes reconstituições e interpretações, as quais não são ideologicamente neutras. Para o efeito, apresenta-se uma análise hermenêutica e comparativa de textos que teorizam essa mudança de paradigma. Tomam-se como ponto de partida quatro artigos de Henry Etzkowitz. A visão que deles se extrai assume-se como a narrativa "oficial" que terá tido influência na evolução mais recente da Universidade. Porém, quando essa teorização é confrontada com outras ideias - quer do próprio Etzkowitz quer de um estudo com a chancela da UNESCO -, surgem então algumas incoerências e limitações.

Palavras-chave: desenvolvimento económico; inovação; neoliberalismo; segunda revolução académica; universidade.

\section{Introdução}

As missões que foram sendo atribuídas à Universidade ao longo dos tempos, bem como as narrativas sobre as revoluções que os analistas associam à sua evolução, são suscetíveis de uma revisão crítica (Costa, 2016). Este artigo tem por objetivo revelar como a designada "segunda revolução académica”, conceito explicitado no início da próxima secção, é passível de diferentes reconstituições e interpretações. Fazendo assim emergir a visão

\footnotetext{
Este artigo isola e aprofunda parte da investigação feita em "A desvalorização das Humanidades. Universidade, transformações sociais e neoliberalismo" (Costa, 2016). Nesse estudo identificaram-se os condicionalismos políticos, ideológicos, teóricos e institucionais que contribuíram para o fenómeno da desvalorização das Humanidades, ocorrido nas últimas décadas. Como ponto de partida, foi analisada a tendência de decréscimo na adesão à formação em Humanidades no ensino superior, em vários países, sendo 2000 e 2012 os anos de referência dessa evolução. Daí a importância de se terem estudado documentos publicados em torno do ano 2000. Agora, a atenção centra-se nos condicionalismos teóricos, analisando-se em particular a teorização feita por Henry Etzkowitz e coautores.
} 
de sociedade subjacente (a pegada ideológica), o artigo mostra como essa narrativa "oficial" não é ideologicamente neutra.

A mudança de paradigma em foco altera a ideia hegemónica de Universidade. É verdade que a uma ideia pode corresponder uma diversidade de concretizações possíveis. Todavia, Anthony Giddens sustenta que, numa época em que as consequências da modernidade se agudizaram e globalizaram, assiste-se a uma separação entre o espaço e o tempo, separação essa que possibilita "a descontextualização dos sistemas sociais" (Giddens, 2000: 15). E, de facto, como se verá, a Universidade que resulta da segunda revolução académica é uma instituição que se aproxima, como nunca, de um formato comum nas suas diferentes realizações, independentemente do contexto em que se insere. A extensão da sua influência é imensa, característica que Giddens também atribui às instituições: a sua capacidade de afetar a vida de milhões de indivíduos. Daí o interesse e a atualidade desta retrospetiva.

Do ponto de vista metodológico, apresenta-se uma análise hermenêutica e comparativa de discursos escritos associados a duas narrativas distintas, ilustrativas da disrupção em causa. A primeira, elaborada em ambiente académico: uma teorização encabeçada por Henry Etzkowitz, patente em vários dos seus artigos científicos, algumas vezes em coautoria com outros investigadores. A segunda, elaborada com a chancela da UNESCO e materializada em formato de relatório. A interpretação que é feita apoia-se em contributos de outros autores, sempre que tal foi considerado relevante.

\section{A segunda revolução académica teorizada por Etzkowitz e seus colaboradores}

O contributo da Universidade para o desenvolvimento económico de regiões ou países constitui aquela que é habitualmente considerada a terceira missão da Universidade, a partir da qual se teorizou a segunda revolução académica, que estará em curso desde a Segunda Guerra Mundial e, de uma forma mais visível, após o fim da Guerra Fria. Pode mesmo dizer-se que a transferência de conhecimento e de tecnologia para a sociedade é o contributo expectável da Universidade, de acordo com a sua nova missão, adquirindo esta instituição maior relevância no sistema de inovação, nomeadamente no campo industrial. Esta evolução é vista como significando uma mudança de paradigma: de uma Universidade "torre de marfim" para uma Universidade "empresarial". Veicula-se a ideia de que no início do século XXI já estavam dados passos consistentes nesse sentido e que já seria comum as universidades estarem formatadas dessa forma (Etzkowitz e Leydesdorff, 2000; Etzkowitz, 2001).

Todo um novo enquadramento teórico se foi construindo, de forma a permitir uma melhor compreensão do fenómeno de inovação, no qual a Universidade passa a ser um ator-chave, entre outros. O primeiro modelo de 
inovação, o modelo linear, já posterior à Segunda Guerra Mundial, considera-se desajustado (Etzkowitz e Leydesdorff, 2000). No final da década de 1980, surge o conceito de sistema nacional de inovação, o qual sugere que a finalidade do sistema de investigação é a inovação, sendo este parte de um sistema mais complexo, composto por setores tais como a indústria, o governo e a universidade (Godin, 2007). Esta abordagem sistémica da inovação deve-se à Organização para a Cooperação e Desenvolvimento Económico (OCDE) e começou a ser pensada já desde a década de 1960, como - de acordo com o autor citado - o testemunham diversos trabalhos publicados. Embora a OCDE não se possa considerar o único elemento que desencadeia esta conceptualização, mesmo assim "a OCDE tem sido desde o início um utilizador sistemático desta abordagem sistémica e, em termos políticos, uma influência entre os seus estados membros" (Godin, 2007: 5).

Através do conceito posterior de tripla hélice (triple helix) relativo às relações que se estabelecem entre universidade-indústria-governo, da autoria de Henry Etzkowitz (1993) e também desenvolvido com Loet Leydesdorff num artigo de 1995, considera-se que o potencial para a inovação e para o desenvolvimento económico tem dois pilares: por um lado, a atribuição de um papel mais proeminente à Universidade e, por outro lado, a hibridação de elementos oriundos dos três setores referidos, com o objetivo de gerar novos formatos, institucionais e sociais, de produção, transferência e aplicação do conhecimento (Triple Helix Research Group, s.d.).

A formalização do tema da tripla hélice e a sua disseminação é feita a vários níveis, nomeadamente pela sua teorização em publicações científicas e pela criação de uma série de conferências que lhe são dedicadas (The Triple Helix Series of Conferences onde se juntam quer académicos quer analistas políticos, tendo a primeira sido realizada em 1996, em Amsterdão e a décima quarta em 2016, na Alemanha). A sua institucionalização efetiva-se, ainda, através do The Triple Helix Research Group, da Universidade de Stanford. Nesse âmbito, a universidade empresarial (entrepreneurial university) surge como um conceito central (Triple Helix Research Group, s.d.).

Gera-se a expectativa de que o conhecimento seja produzido no contexto da sua aplicação (Godin e Gingras, 2000). Assim se consolida uma solução para a situação problemática que Michael Gibbons identificava nos seguintes termos: "Mais de $90 \%$ do conhecimento produzido globalmente não é produzido onde o seu uso é necessário" (Gibbons, 1998: i).

Esta forte vinculação da Universidade à produção de inovação simboliza de tal forma uma rutura com o que acontecia até então que a ela se associa também uma mudança na própria ideia de sociedade: de uma sociedade 
industrial, díade indústria-governo, para uma sociedade do conhecimento, tríade indústria-governo-universidade (Triple Helix Research Group, s.d.). Em 2000, Etzkowitz e Leydesdorff preconizaram que, no futuro, o critério para a legitimação da atividade científica e do seu financiamento, seria cada vez mais o contributo para o desenvolvimento económico. Os anos que se seguiram não os contradisseram.

\section{Analepse 1:}

\section{o pensamento não dominante de Etzkowitz e dos seus colaboradores}

Uma segunda análise ao pensamento de Etzkowitz, e dos seus coautores, permite reconhecer que, afinal, a Universidade contribuiu para o desenvolvimento económico ainda antes da segunda revolução académica.

A ciência sempre foi organizada através de redes e tem seguido interesses práticos e teóricos [...] A dissertação de Merton (1938) reporta que entre 40\% a 60\% das descobertas feitas no século XVII podem ser classificadas como tendo as suas origens na tentativa de solucionar problemas de navegação, de mineração, etc. (Etzkowitz e Leydesdorff, 2000: 115-116)

Se, desde sempre, a ciência teve por objetivo solucionar problemas concretos, então é possível tirar uma conclusão diferente daquela que foi retirada na secção anterior: o contributo da Universidade para o desenvolvimento, mesmo contemplando a sua vertente económica, terá passado, naturalmente, a ser uma missão da Universidade no século XIX, quando esta instituição passou também a ter por incumbência a investigação científica, ou seja, aquando da primeira revolução académica. Desconstrói-se, assim, o entendimento da novidade da terceira missão da Universidade, tida como a contribuição para o desenvolvimento económico, e balizada temporalmente a partir do fim da Guerra Fria.

Outras afirmações concorrem para esta conclusão. Basta relembrar o momento em que Etzkowitz e Leydesdorff mostram estar em discordância com a posição teórica de Michael Gibbons relativamente ao modo 1 e ao modo 2 de produzir conhecimento. ${ }^{1}$

\footnotetext{
${ }^{1}$ O que o processo de produção de conhecimento modo 2 acrescenta ao processo de produção de conhecimento modo 1 é o facto de o conhecimento ser produzido no contexto da aplicação, de ser produzido em ambiente transdisciplinar, em organizações diversas e heterogéneas, com maior responsabilidade social e com um controlo de qualidade mais apurado (Gibbons, 1998). No modo 1, o cientista trabalharia isoladamente, independentemente dos interesses da sociedade (Etzkowitz e Leydesdorff, 2000).
} 
O assim designado modo 2 não é novo: é o formato original da ciência antes da sua institucionalização académica no século XIX [...] O modo 2 representa a base material da ciência, como na verdade ela funciona. O modo 1 é um constructo, destinado a justificar a autonomia da ciência. (Etzkowitz e Leydesdorff, 2000: 117)

No artigo citado, a ideologia da ciência pura (correspondente ao referido modo 1) é considerada como uma resposta a situações históricas particulares quando, por uma razão ou por outra, foi necessário construir um espaço independente para a ciência. Contudo, esta ideologia não é assimilada igualmente por todas as universidades:

Claro que, ao mesmo tempo que as liberal arts universities estavam orientadas para a investigação pura aquando da sua fundação, as land grant universities, incluindo o MIT, seguiam estratégias de investigação mais práticas. Estas duas formas académicas contrastantes coexistem há muitos anos. (ibidem: 116)

Mesmo no que diz respeito à relação específica entre as empresas e a Universidade, Etzkowitz considera que essa relação se tem vindo a estabelecer, nos Estados Unidos da América (EUA), já desde os finais do século XIX, tendo passado por três estádios: primeiramente, uma relação filantrópica; depois, a formação dos potenciais empregados das empresas; e, por último, a realização de investigação ajustada às necessidades das empresas (Etzkowitz, 1993). O exemplo que o autor dá do Massachussetts Institute of Technology (MIT) reforça a constatação de que a novidade da segunda revolução académica não será o contributo para o desenvolvimento económico. Este Instituto, ainda antes da Segunda Guerra Mundial, durante a depressão iniciada em 1929, ou seja, antes do início da segunda revolução académica, teve dificuldade em obter apoio político para concretizar o seu interesse em contribuir para o desenvolvimento local (ibidem).

Karl Compton (1887-1954), então presidente do MIT (cargo que exerceu entre 1930 e 1948), afirmava que a investigação científica poderia ser uma força orientadora da economia na Nova Inglaterra. Um elemento-chave na concretização desta visão foi o desenvolvimento de mecanismos para a transferência de tecnologia, tais como empresas de capital de risco (the venture capital firm), as quais serviam para juntar capitalistas e empresários com investigadores académicos e engenheiros, criando-se assim oportunidades para transformar os resultados da investigação em produtos comerciais. "Era uma alternativa a procurar um espaço adequado para a nova tecnologia numa empresa já existente, ou a deixá-la por desenvolver quando esse espaço não era encontrado" (ibidem: 343). Todavia, só após 
a Segunda Guerra Mundial é que foram elaboradas políticas e estabelecidos mecanismos organizacionais para regulamentar e promover empresas desse tipo (Etzkowitz, 1993), muitos anos depois de Compton ter dado início aos seus esforços concretos para obter um apoio dessa natureza.

O caso do MIT revela a anterioridade da determinação de contribuir para o desenvolvimento económico que se encontra na Universidade, face à posterioridade da institucionalização das políticas promotoras da ciência e da tecnologia que surge no pós-Segunda Guerra Mundial. A criação de duas instituições foi, para esse propósito, fundamental.

A nível internacional, surge a OCDE, uma das organizações internacionais que irá condicionar, em grande medida, as políticas de ciência, tecnologia e inovação. A sua atividade inicia-se em 1948, ainda que 1960 seja considerado o momento do seu começo formal. ${ }^{2}$ Um pouco antes, em julho de 1945, é publicado nos EUA o relatório de Vannevar Bush, intitulado Science The Endless Frontier. ${ }^{3}$ Nesse relatório, dirigido a Franklin Roosevelt, é proposta a criação da National Research Foundation, sugestão que foi finalmente concretizada em 1950, com a criação da National Science Foundation (NSF).

Segundo Benoît Godin, a origem do modelo linear de inovação - "investigação básica $\rightarrow$ investigação aplicada $\rightarrow$ desenvolvimento $\rightarrow$ produção e difusão" (2005: 4) - nem sempre é bem delimitada. O autor admite que muitos daqueles que o referem não identificam a fonte da informação e que outros consideram que esse modelo tem origem no citado relatório de Bush. Já para David Wolfe, o modelo linear da inovação foi idealizado num relatório inicial da NSF, subjacente à emergência do contrato social para a ciência: um forte investimento público na investigação básica, apostando nos seus benefícios económicos a longo-prazo e garantindo a autonomia da investigação no âmbito das universidades (Wolfe, 2005).

O que importa reter é que, logo após a Segunda Guerra Mundial, a investigação científica é perspetivada em termos de inovação, mas com abertura para a investigação fundamental, a autonomia da Universidade e o longo prazo. Foi o tempo do modelo linear de inovação: os estrategas reconhecem o potencial da ciência para o desenvolvimento económico, mas, antes de mais, dão espaço e tempo ao conhecimento, a todo o conhecimento. Numa fase posterior, nos fins da década de 1980, quando o modelo linear de inovação é considerado insuficiente para transferir conhecimento e tecnologia para a economia, começa a narrativa da segunda revolução académica, relatada no ponto precedente.

\footnotetext{
${ }^{2}$ De acordo com http://www.oecd.org/about/history/. Consultado a 12.05.2015.

${ }_{3}$ Disponível em https://www.nsf.gov/od/lpa/nsf50/vbush1945.htm. Consultado a 30.05.2015.
} 
Com essa mudança de paradigma, inicia-se então o tempo da tripla hélice e da visão sistémica da inovação que, como que deslumbrada com os ovos de ouro, transporta em si a perversidade de colocar em risco quer a autonomia da Universidade, nomeadamente face aos poderes político e económico, quer a abrangência da visão que faz dela uma instituição equilibrada entre várias missões e entre vários domínios do conhecimento. Por este prisma, a segunda revolução académica pode mesmo significar um certo retrocesso relativamente à primeira, a qual tem os seguintes traços característicos: a autonomia da Universidade face aos poderes instituídos na sociedade, a integração de todos os domínios do conhecimento e a consolidação da investigação com o ensino (Costa, 2016).

Depois desta analepse, é difícil aceitar que a essência da segunda revolução académica consista no contributo da Universidade para o desenvolvimento económico. Mas é nestes termos que, de facto, a questão é colocada: "Pode a academia abranger uma terceira missão de desenvolvimento económico, para além da investigação e do ensino?” (Etzkowitz e Leydesdorff, 2000: 110).

Assim sendo, pode-se concluir que a novidade da segunda revolução académica não será tanto o contributo da Universidade para o desenvolvimento económico - este ter-se-á concretizado de diferentes modos e segundo diferentes intensidades ao longo do tempo, até mesmo indiretamente pela missão de ensino. Também não será o reconhecimento político desse contributo: com o fim da Segunda Guerra Mundial, a inovação já era teorizada, nomeadamente no contexto da OCDE. O que emerge como crucial é, então, o processo de mudança do entendimento sobre a valorização do conhecimento, sendo nessa ordem que se alterou o paradigma. Antes de a terceira missão ser equacionada como tal, ela já estava implícita na Universidade, mas de uma forma que não menorizava ou esmagava outras dimensões. Depois, essa vertente adquiriu um reconhecimento sistemático, externo à Universidade e de cariz político, adquirindo uma tal amplitude que, a par de suportes ideológicos fortes, acarretou também mudanças profundas ao nível dos princípios de organização e gestão das universidades. Desta forma, esta instituição foi vestindo o formato empresarial que atualmente lhe é associado.

Sintetizando: quando muito, o que é novo nesta forma de ver a segunda revolução académica será o empenho em instrumentalizar o conhecimento gerado na Universidade para fins económicos.

A dimensão política da inovação é clara na argumentação de Godin - "Ciência é método enquanto inovação é política" (Godin, 2014a: 6). Primeiro, houve a necessidade de compreender o processo de inovação 
e, depois, passou a haver um conjunto de teorias que possibilitaram a elaboração e a implementação de políticas económicas, nas quais a inovação tecnológica é um instrumento (Godin, 2014b). Indústria, economistas, gestores e governos ancoraram a inovação no universo dos bens tecnológicos, das empresas e dos mercados. Para este entendimento particular da inovação também contribuíram os cientistas sociais.

Aquilo que os cientistas sociais do século XX - em colaboração, aliás, com os governos - acrescentaram ao estudo da inovação foi o contributo da inovação tecnológica para o desenvolvimento económico nacional. Este tem tido uma influência pronunciada enquanto fundamento para o desenvolvimento de políticas para o estímulo da inovação tecnológica. Por sua vez, estas políticas têm tido um papel importante na transformação do conceito de inovação num termo popular ao longo das últimas décadas. (Godin, 2014a: 38)

Ou seja, o reconhecimento da terceira missão da Universidade em termos do seu contributo para o desenvolvimento económico, nomeadamente através da inovação tecnológica, encontra também os seus alicerces no interior da própria instituição académica. Os desenvolvimentos teóricos deram um fundamento à ação política. Segundo Weiler (2006), o conhecimento e o poder caracterizam-se por esta capacidade de se legitimarem reciprocamente.

Na próxima secção, constata-se como a visão etzkowitziana da segunda revolução académica é redutora das dinâmicas do ensino superior, não dando conta da sua complexidade. Todavia, como se verá, essa limitação não foi um obstáculo a que a Universidade seguisse o destino que lhe estava previsto.

\section{Analepse 2:}

\section{a segunda revolução académica vista sob os auspícios da UNESCO}

Em Trends in Global Higher Education: Tracking an Academic Revolution, relatório publicado pela UNESCO (Altbach, Reisberge e Rumbley, 2009), são analisadas as tendências associadas ao ensino superior nos últimos 50 anos, embora se foque sobretudo a fase a partir de 1998. Reconhece-se que a envergadura das mudanças que ocorreram nesse período justifica que se afirme que se está perante uma revolução académica. Esta revolução, então ainda em curso, foi modelada por transformações sem precedentes no alcance e na diversidade. Quando comparada com a primeira revolução académica, no século XIX, esta é considerada igualmente marcante, tendo em conta o grau de rutura por referência ao ponto de partida, mas é mais 
abrangente devido à sua natureza global e ao número de instituições e de pessoas envolvidas.

A primeira dinâmica característica da revolução académica analisada é o processo de massificação do acesso ao ensino superior: "A expansão do ensino superior foi o âmago da realidade do setor na última metade do século xx e na atualidade" (Altbach, Reisberg e Rumbley, 2009: 5). ${ }^{4}$ A procura do ensino superior foi, talvez, a força social mais poderosa em muitos países, numa altura em que o ensino superior passou a ser visto como um passo necessário para a mobilidade social e o sucesso económico. A reforçar esta causa, destaca-se o "baby boom" que se verificou após a Segunda Guerra Mundial, na América do Norte e na Europa. A partir daí, aconteceram profundas mudanças económicas, que geraram uma intensificação da procura de profissionais com habilitações académicas: a mudança para as economias pós-industriais, o aumento das indústrias de serviços, a chegada da tecnologia às economias tradicionais e a emergência da economia do conhecimento. Em particular, esta última, considerada no relatório também como sendo uma realidade central do século XXI, é vista pelos seus autores como promotora da formação académica superior, da relevância da investigação científica em determinadas áreas e da mobilidade global dos profissionais altamente treinados (ibidem).

Os relatores fazem um balanço da situação: ainda que, num primeiro estádio, os sistemas de ensino superior tenham dado resposta à crescente procura, à necessidade de expandir as infraestruturas e de alargar o corpo de professores, nos inícios do século XXI, em muitos países, os estudantes têm ainda de competir pelas vagas disponíveis e tornou-se mais difícil entrar nas instituições de topo. Trata-se, assim, de um processo de massificação inacabado, ${ }^{5}$ cujo sucesso futuro não se considera facilitado. O relatório da UNESCO, que faz eco das previsões da OCDE, aponta para que o crescimento do número de estudantes se mantenha, assim como

\footnotetext{
${ }^{4}$ Mesmo por outros autores, ela é considerada a mudança mais radical no ensino superior. Por exemplo, "Uma das transformações mais notáveis [dramatic] no ensino superior durante a última metade do século xx foi este deixar de ser para as elites (educação para poucos) e ter-se massificado (educação para todos os qualificados)" (Morey, 1992: 1526).

${ }^{5}$ Nos primórdios da massificação do acesso ao ensino superior em Portugal, ainda antes da segunda revolução académica começar a ser formulada, Miller Guerra e Sedas Nunes, em oposição ao carácter anquilosado e elitista da Universidade em Portugal, equacionavam esse fenómeno com base em ideias promotoras de justiça social. "O que se torna necessário, em tal situação [em caso de congestionamento das instituições universitárias], não consiste, portanto, em refrear o crescimento do número de estudantes, mas em ampliar e adaptar as estruturas do sistema" (Guerra e Nunes, 1969: 10-11). Esta clareza de pensamento caiu, infelizmente, em desuso, tendo ganho expressão e sido implementadas as ideias que se alimentaram dos princípios neoliberais, então em estado embrionário.
} 
o crescimento dos próprios sistemas de ensino superior (afirma-se que só em poucos países se assistirá a uma contração do número de estudantes) e, de uma forma geral, assume-se que os custos continuam a ser uma grande barreira para o acesso à Universidade.

A globalização é outra das dinâmicas que caracterizam a atualidade do ensino superior e também ela não tem concorrido para uma democratização efetiva do ensino universitário. Ainda que as universidades sempre tenham sido afetadas por tendências internacionais e sempre se tenham encontrado inseridas num contexto internacional, os relatores entendem que, no século XXI, essas dinâmicas adquiriram uma maior importância, nomeadamente devido às novas tecnologias de informação e comunicação (TIC).

Em geral, as TIC são consideradas como uma força global, "uma das influências mais poderosas", que afeta o ensino superior em qualquer lado e a vários níveis (Altbach, Reisberg e Rumbley, 2009:3). No entanto, persistem profundas desigualdades no que diz respeito ao acesso, uso e influência destas tecnologias. Assim, certas universidades foram favorecidas, na medida em que as TIC têm permitido concentrar a propriedade de editoras, bases de dados e outros recursos-chave nas universidades mais fortes e em algumas multinacionais, localizadas tendencialmente no mundo desenvolvido. O predomínio da língua inglesa que, como língua de comunicação científica não tem precedentes, ${ }^{6}$ contribuiu para tal. Assiste-se, então, a uma explosão de programas e instituições internacionais, à mobilidade de estudantes e de académicos.

Como consequência, gera-se um movimento, sobretudo de Sul para Norte que, por fragilizar mais o Sul, gera também uma preocupação com o equilíbrio internacional de recursos, quer institucionais, quer humanos. Paralelamente, tem também aumentado a dificuldade e a desigualdade no acesso ao ensino superior, sobretudo naquelas que podem ser consideradas como as "melhores" universidades, quer a nível internacional, quer dentro de um mesmo país, beneficiando as classes mais altas da vantagem dessa sua condição, mesmo em países onde a inclusão social já tem feito o seu caminho (Altbach, Reisberg e Rumbley, 2009). Para Nussbaum, esta situação é inadmissível, no sentido em que "nenhum sistema de educação está a fazer um bom trabalho se beneficia só elites ricas. A distribuição do acesso a uma educação de qualidade é uma questão urgente em todas as democracias modernas" (Nussbaum, 2010: 11).

Os conceitos de globalização e de mercado surgem associados. "A mobilidade académica é um distintivo da era global. Hoje existe um verdadeiro

\footnotetext{
${ }^{6}$ Se se excluir, como é salvaguardado no relatório, o domínio do latim na academia da Europa medieval.
} 
mercado global para os estudantes e o staff académico" (Altbach, Reisberg e Rumbley, 2009: 3). A diminuição do investimento público acompanhou o processo de globalização, facilitando a emergência da iniciativa privada. Sousa Santos pronuncia-se sobre a indissociabilidade destes fenómenos, assim como identifica a raiz neoliberal destas transformações (Santos, 2008).

Os dois processos [...] o desinvestimento do Estado na universidade pública e a globalização mercantil da universidade [...] são as duas faces da mesma moeda. São os dois pilares de um vasto projecto global de política universitária destinado a mudar profundamente o modo como o bem público da universidade tem sido produzido, transformando-o num vasto campo de valorização do capitalismo educacional. (ibidem: 21)

Do ponto de vista do financiamento do ensino superior, os relatores da UNESCO indicam que o aumento do número de estudantes representou o maior desafio para os sistemas que tradicionalmente providenciavam um acesso livre ou altamente subsidiado ao ensino superior. No seu entender, este ter-se-á tornado um modelo insustentável, dado que as receitas fiscais não acompanharam o aumento dos custos do ensino superior (Altbach, Reisberg e Rumbley, 2009).

Para além da tendência de expansão do número de alunos no ensino superior, quando o relatório da UNESCO é publicado, era claro que se vivia no meio de uma profunda crise económica, assim como se reconhecia que essa crise teria repercussões - "de modos que ainda não são óbvios" na sociedade em geral e, em particular, no ensino superior, como há muito (desde a Segunda Guerra Mundial) não acontecia com tal gravidade - "o ensino superior está a entrar num período de cortes significativos" (ibidem: 4-5). ${ }^{7}$

Com a justificação da insuficiência dos dinheiros públicos, foi necessário que as instituições alargassem as suas fontes de receitas. Pais e/ou estudantes foram chamados a assumir o encargo das propinas ou outros custos, mesmo na Europa, "o bastião do ensino superior público gratuito" (ibidem: xii). As instituições do ensino superior também se tornaram responsáveis por gerarem largas percentagens de receitas próprias.

\footnotetext{
${ }^{7}$ Abrindo um parêntesis na análise do relatório, atente-se que, se este tiver sido publicado no primeiro semestre de 2009 (a conferência para a qual foi preparado realizou-se de 5 a 8 de junho de 2009), a crise financeira de 2008 não poderá ter sido determinante para a evolução do ensino superior no período em estudo. Assim, a pressão para se reestruturar o contrato social estabelecido entre o ensino superior e a sociedade no seu todo, radicará numa necessidade - anterior a essa crise - de não aumentar o investimento público na proporção do número de alunos que o pretende frequentar, ou seja, numa escolha político-ideológica decidida pelos governantes.
} 
Do lado da despesa, o relatório aponta várias das soluções adotadas para enfrentar a escassez de recursos, que levaram a um aumento da austeridade nas universidades e que afetaram necessariamente a qualidade do ensino: salas de aulas superlotadas, fundos documentais desatualizados nas bibliotecas, menos apoios para a investigação, deterioração de edifícios, perda de segurança nas posições de docente, fuga dos cérebros mais talentosos. A confiança no setor público universitário diminuiu, um fenómeno de desacreditação que ocorreu em todo o setor público em geral.

Contudo, esta mudança na lógica do financiamento - que terá tido e continuará a ter, evidentemente pelo que já foi dito, implicações ao nível da igualdade de oportunidades - não é só associada ao fenómeno da massificação, mas também à visão neoliberal. O relatório prossegue e nele se afirma que, em consequência, a própria conceção de ensino superior se transformou.

Se tradicionalmente o ensino superior era considerado um bem público da responsabilidade do Estado, na medida em que contribui para a sociedade através da educação dos cidadãos, melhorando o capital humano, encorajando a participação cívica e impulsionando o desenvolvimento económico, nas últimas décadas o ensino superior passou a ser, cada vez mais, visto como um bem privado, em larga medida beneficiando indivíduos. Daí que, como mencionado atrás, a par dos novos modelos de financiamento público também se assistiu à crescente privatização do ensino superior. Trata-se de um modelo de negócio, com poder e autoridade concentrados em conselhos e chefes executivos, com uma pequena influência dos professores e com os estudantes considerados como consumidores. No entanto, a confiança na universidade privada também não abarca todas as suas instituições (Altbach, Reisberg e Rumbley, 2009). Uma nova face da desigualdade de oportunidades no ensino superior torna-se evidente: quem menos tem, mas ainda consegue pagar um curso no privado, ainda tem que suportar o facto de a sua universidade poder ser considerada de segunda categoria.

Esta desconfiança que assolou universidades, públicas e privadas, fez com que a garantia da qualidade no ensino superior se tenha tornado uma preocupação de topo na agenda política de vários países. Tal como se pode concluir da leitura do relatório, no entanto, o caminho tomado não foi o de assegurar para todos a qualidade do ensino (posição coerente se criticamos o desinvestimento que aconteceu no ensino superior público), mas, em sentido oposto, criar mecanismos que permitissem, a quem pode escolher, a identificação do ensino excelente (posição coerente com quem critica a abertura do ensino superior, com qualidade, para todos).

O relatório é perentório no que diz respeito à importância dada à questão da qualidade no ensino superior: "a garantia da qualidade no ensino 
superior chegou ao topo da agenda política em muitas nações” (Altbach, Reisberg e Rumbley, 2009: x). Esta preocupação tornou-se mais premente com a crescente mobilidade dos estudantes; daí, a necessidade de, à escala internacional, estandardizar a certificação das instituições e das qualificações que estas atribuem, de acordo com os interesses dos seus consumidores - mais uma vez, o emprego de um termo próprio de uma relação comercial: "'consumidores' da educação (estudantes, pais, empregadores)" (ibidem: xi). No entanto, os autores reconhecem um estado de incoerência: os mecanismos que possibilitam esta comparabilidade internacional são ainda poucos e pouco testados. Acrescentamos que, para além disso, são controversos. ${ }^{8}$

Em particular, os autores do relatório em análise assumem que os rankings internacionais, que hierarquizam ou qualificam de alguma maneira as universidades, favorecem aquelas que usam o inglês como língua principal de ensino e de investigação, que têm uma ampla gama de disciplinas e de programas, e que podem dedicar financiamentos substanciais à investigação. Reconhecem ainda que, apesar dos problemas metodológicos que estes rankings têm, estes são largamente usados e influentes, "e não mostram sinais de desaparecimento" (ibidem: iv). Através deles, são favorecidas determinadas universidades, determinados países e determinados indivíduos (sobretudo os que têm meios - dinheiro e informação - para procurar as melhores universidades). Se tivermos em conta a perspetiva de Lynch, esta dinâmica manifesta uma faceta neoliberal: "o movimento para criar rankings globais para a universidade é simbolicamente o indicador mais poderoso de que os valores de mercado foram incorporados no setor universitário" (Lynch, 2006: 5). Lynch explicita mesmo que, relativamente à educação, essa ideologia foi mais longe que o liberalismo, no sentido em que subordinou e trivializou a educação que não tem valor de mercado.

Ficou para o fim desta secção a referência às mudanças que ocorreram na organização e gestão das universidades. No relatório da UNESCO, reconhece-se como o conceito de tripla hélice (triple-belix of university-government-industry linkages) originou mudanças organizacionais importantes na Universidade (que serão detalhadas mais à frente). Refere-se, em particular, que foram desenvolvidos os special offices e que estes prosperaram e ajudaram a gerar novas fontes de receitas para as instituições de ensino superior. As universidades, de forma a potenciarem as

\footnotetext{
${ }^{8}$ Isto não significa que não se tenham desenvolvido esforços para melhorar estes instrumentos de aferição da qualidade das instituições do ensino superior. A plataforma U-Multirank é disso exemplo: no seu âmbito, já é possível comparar universidades de todo o mundo em múltiplas dimensões. Plataforma disponível em https://www.umultirank.org/, consultada a 30.06.2015.
} 
suas receitas, protegem a propriedade intelectual. Ou seja, a investigação é realizada num contexto onde há pressão e necessidade de comercializar o conhecimento.

Resume-se a evolução da Universidade tal como foi vista em 2009 pelos relatores da UNESCO: massificação, restrição do investimento público, imposição de austeridade nas instituições, imperativo às instituições no sentido de gerarem mais receitas mesmo sobrecarregando as famílias, visão empresarial da Universidade, ensino superior cada vez mais considerado um bem privado e não - na sua essência - público, comercialização do conhecimento, preocupação com a qualidade de todas as instituições substituída pela procura da excelência de algumas, emergência de um mercado universitário, crescente privatização do setor, competição entre instituições, introdução de rankings, hierarquização das instituições universitárias, aumento da desigualdade de oportunidades de acesso a um ensino de qualidade, uma globalização que fragiliza ainda mais os países mais pobres, acentuando $\mathrm{o}$ afastamento entre o centro e a periferia dos sistemas de ensino superior. O resultado não tem sido brilhante, nomeadamente em termos do regresso do elitismo a esta instituição. De seguida, o foco da exposição passa para a seguinte questão: em que medida este novo retrato da segunda revolução académica coincide com o cenário traçado em 2000 por Etzkowitz e pelos seus colegas?

\section{Comparação das narrativas sobre a segunda revolução académica}

Comparando a narrativa da segunda revolução académica de Etzkowitz com a que é elaborada sob os auspícios da UNESCO, conclui-se que a primeira peca por uma extrema linearidade e simplificação, ao adotar uma perspetiva marcadamente económica (a inclusão do contributo para o desenvolvimento económico como terceira missão da Universidade, sendo esta tida como a essência da segunda revolução académica). Contrastando com isto, o relato da UNESCO revela uma maior riqueza de análise: traça um panorama da segunda revolução muito diferente, faseando-a (há características que, por sua vez, vão influenciar outras características), não se circunscrevendo à dimensão económica e possibilitando a identificação de um conjunto diversificado de fatores envolvidos (sociais, ideológicos, políticos, económicos e tecnológicos).

Se bem que, nove anos depois - o intervalo que medeia as duas publicações - a evidência da realidade seja outra (basta pensar que, entretanto, ocorreu a crise global de 2008), ${ }^{9}$ muitas das dinâmicas constatadas no

\footnotetext{
${ }_{9}$ Embora ainda, decerto, sem grandes implicações num relatório publicado em 2009.
} 
relatório da UNESCO já existiam antes..$^{10}$ Não obstante, o potencial de explicação da segunda narrativa acaba por ser muito superior.

Pese embora a diferença apontada entre as duas narrativas, a visão reducionista que ignora os bloqueios a um desenvolvimento sustentável e democratizante do ensino superior, versus a visão abrangente e realista sobre o que mudou no ensino superior, podem-se-lhes atribuir duas coincidências. Em primeiro lugar, ambas aceitam que, ainda que haja diferentes soluções no equilíbrio que se estabelece entre as três missões da Universidade, tendencialmente há pouca diversidade; a questão de fundo é a convergência para uma mesma dinâmica (a prioridade à terceira missão, quer pelo ensino quer pela investigação). Por outro lado, as duas narrativas concordam que tendencialmente se constata a implementação de um formato comum, quanto a princípios de organização e gestão das universidades. Mostra-se de seguida como, em cada uma das narrativas, se esclarece como foi adotado esse formato e como é que, cada uma das narrativas, considera que isso seja conciliável com as várias missões da Universidade.

$\mathrm{Na}$ ótica de Etzkowitz e dos seus colaboradores, a adoção de uma gestão de tipo empresarial nas universidades resulta tanto de um desenvolvimento interno da própria instituição (suscitado pelas vantagens financeiras associadas) como de influências externas (a necessidade de promover o desempenho económico regional e nacional). Reconhecem, no entanto, que muitos (académicos e não só) consideram este novo paradigma empresarial um risco para a própria Universidade: "o paradigma empresarial como uma ameaça à integridade tradicional da Universidade” (Etzkowitz et al., 2000: 314). Apesar disso, também reconhecem a inevitabilidade dessa transformação: “o ímpeto para a emergência da 'universidade empresarial' é excecionalmente forte, mesmo que o seu desenvolvimento coloque questões institucionais e de governança importantes para os envolvidos" (ibidem).

Aqueles autores afirmam que, depois de séculos durante os quais se divergiu de um modelo único para a Universidade, a emergência de um "modelo empresarial" - "a universidade empresarial", "o paradigma empresarial", "a identidade empresarial", "a cultura empresarial na academia" (ibidem: 313-315) - é a resposta à crescente importância do conhecimento nos sistemas de inovação (nacionais ou regionais) e ao reconhecimento do papel da Universidade nesse âmbito. A abrangência global deste movimento de mudança também é sublinhada: verifica-se em qualquer parte do mundo,

${ }_{10}$ Aliás, no relatório da UNESCO, sublinha-se o facto de a maior parte destas tendências não serem novas, de terem sido já constatadas num relatório de 1998 intitulado World Declaration on Higher Education for the Twenty-First Century: Vision and Action, and Framework for Priority Action for Change and Development in Higher Education; o que aconteceu, em geral, foi a sua intensificação. 
independentemente do estado de desenvolvimento da indústria e do sistema académico (Etzkowitz et al., 2000).

Quanto ao modo como o formato empresarial coexiste com as várias missões que uma universidade pode enquadrar, considera-se que o novo formato também se aplica às universidades de ensino e de investigação, constatando-se que a separação do ensino, da investigação e das atividades de negócios se torna menos sustentável. Um ano mais tarde, Etzkowitz descrevia do seguinte modo os efeitos do modelo empresarial aplicado ao ensino superior:

as universidades empresariais estão a remodelar a paisagem académica ao transformarem o conhecimento em propriedade intelectual [...] Como o seu interesse em ganhar dinheiro a partir dos seus recursos de investigação cresce, as universidades competem numa nova arena. (Etzkowitz, 2001: 18)

A expressão que melhor sintetizará aquilo que o autor entende por nova arena será a expressão capitalização do conhecimento. ${ }^{11}$ Fica implícito que não será todo o conhecimento que será protegido e promovido, porque se manifesta preferência pelo conhecimento que se transforma em propriedade intelectual e, desta forma, se pode transformar em dinheiro.

A visão da UNESCO tem um alcance maior. Os seus relatores reconhecem, também eles, como o conceito de tripla hélice influenciou diretamente a organização da Universidade e, na sua constatação, até a terminologia que passa a ser utilizada coincide com uma visão empresarial da Universidade: por exemplo, gerar receitas com a propriedade intelectual, com a comercialização do conhecimento. Mas, como já foi expresso, os autores do relatório inserem esta forma de conceber o conhecimento num contexto ideológico que considera o ensino superior como um bem privado. No entanto, salvaguardam que esta visão da Universidade não é consensual, existindo mesmo, a par dessa visão, posições antagónicas.

A investigação de base universitária está a ser conduzida num ambiente onde há pressão e necessidade de comercializar o conhecimento, mas ao mesmo tempo existe a pressão oposta para tratar a produção do conhecimento e a sua disseminação como um bem público. (Altbach, Reisberg e Rumbley, 2009: xiv)

Quanto à forma como a nova gestão da Universidade coexiste com as várias missões da instituição, os autores do relatório da UNESCO têm uma

11 "A capitalização do conhecimento representa a transformação do papel da Universidade na sociedade, comparável à primeira revolução académica” (Etzkowitz, 2001: 19). 
posição muito menos conciliadora do que a da narrativa de Etzkowitz. Consideram que, em particular, são postas em causa a função social e a função de serviço público da Universidade, funções que consideram ser centrais na sociedade contemporânea (Altbach, Reisberg e Rumbley, 2009).

Este cotejo põe a nu que, independentemente da justificação que possa ser dada, se instituiu tendencialmente uma visão empresarial da Universidade, da qual resulta a convergência para um determinado formato de organização e gestão desta instituição. Assim, foi priorizada a sua missão de contribuir para o desenvolvimento económico, ainda que com o atropelo de outras das suas funções e de determinados domínios do conhecimento. E, sublinhamos, esta foi uma evolução que pôs entraves à possibilidade da mobilidade social.

Segundo Naomar de Almeida Filho, a reforma concretizada na Universidade foi mais do que uma mera reforma organizacional. Este autor fala também expressamente numa mudança de paradigma e situa-a "no final do século Xx, num contexto económico e político que ganhou o nome de neoliberalismo" (Almeida Filho, 2008: 123). Esta ligação já foi muitas vezes reconhecida, como por exemplo: "subjacente à orientação para o mercado da educação terciária está a ascendência, quase mundial, do capitalismo de mercado e dos princípios económicos neoliberais" (Johnstone, Arora e Experton, 1998: 4). No decurso deste artigo já se tinham incluído outras pistas nesse sentido. Diversos autores - Belfiore, 2004; Deem e Brehony, 2005; Olssen e Peters, 2005; Archer, 2008; Gewirtz e Cribb, 2013 - associam diretamente a nova abordagem da gestão da administração pública (new public managment e new managerialism), onde se enquadra a reforma organizacional da Universidade pública, à ideologia neoliberal. O conceito de capitalismo académico é também importante no esclarecimento destas dinâmicas (entre várias publicações, Rhoades e Slaughter, 2004).

\section{Conclusão}

A reflexão feita sobre a segunda revolução académica, tal como foi teorizada por Etzkowitz e seus colaboradores, sobre o que nela é pretensamente novidade ou sobre o que nela é realmente novo, assim como a identificação da distância que a separa das dinâmicas do ensino superior específicas das últimas décadas, poderão contribuir para uma postura crítica relativamente ao modelo atual e predominante de Universidade. A terminar, são de salientar algumas ideias.

Nas décadas mais recentes, algumas das medidas políticas que se foram arquitetando para dar resposta à crescente procura do ensino superior não contribuíram para dar uma continuidade sustentável - de qualidade e equitativa - a essa dinâmica, acentuando mesmo uma desigualdade de 
oportunidades a vários níveis, como explicitado no decurso deste artigo. Ao invés, cresceu a preocupação reverente pelos mercados, instalou-se a governação da coisa pública de acordo com uma lógica empresarial privada e assistiu-se à crescente privatização do setor, marcas que constituem a pegada ideológica da segunda revolução académica.

A Universidade foi-se ajustando paulatinamente a um modo de ser neoliberal, também apoiada em argumentos científicos, aparentemente despidos de uma linha ideológica. Uma análise contextualizada do número de citações de duas das publicações mais citadas neste artigo (Etzkowitz e Leydesdorff, 2000 e Etzkowitz et al., 2000) reforça a ideia de que esses trabalhos foram seminais. Foram influentes, apesar de conterem em si linhas de argumentação não de todo coerentes e de ignorarem dimensões importantes da vida em sociedade, para além da economia. Este é mais um caso que evidencia como poder e conhecimento podem interagir entre si.

E enquanto a Universidade esteve, e está, sobretudo focada na preocupação com o desenvolvimento económico, pressionada pelas políticas internacionais e nacionais, sem que uma onda suficientemente forte de pensamento crítico tenha conseguido abalar essa visão dominante, a sociedade continuou a evoluir, sendo os desafios mais prementes com que atualmente se confronta de natureza diversa, alguns de extrema gravidade, mais ou menos diretamente interconectados entre si: para além dos de foro económico, desafios ambientais, geopolíticos, societais e tecnológicos (riscos globais identificados em World Economic Forum, 2017).

Do ponto de vista da investigação futura, sugere-se a monitorização crítica das atuais políticas de ensino superior e de investigação científica, nomeadamente as do âmbito das organizações internacionais, dada a sua influência nas nacionais. A finalidade será compreender em que medida estas podem ser um entrave à abrangência da missão da Universidade (por um lado, no que diz respeito à pluralidade das suas funções e, por outro lado, no que diz respeito à sua abertura, sempre com qualidade, a todos os que a queiram frequentar) e ainda identificar os pressupostos ideológicos subjacentes (as questões de fundo, suscetíveis de alternativa).

De um modo complementar, os mecanismos e critérios de avaliação e financiamento das atividades decorrentes em contexto académico têm de ser pensados e revistos, de forma a valorizarem as várias dimensões de resultados e de impactos societais que se podem esperar da instituição universitária.

Revisto por Sofia Silva 


\section{Referências bibliográficas}

Almeida Filho, Naomar de (2008), "Universidade Nova no Brasil", in Boaventura de Sousa Santos; Naomar de Almeida Filho, A Universidade no século XXI. Para uma Universidade Nova. Coimbra: CES/Almedina, 79-182.

Altbach, Philip G.; Reisberg, Liz; Rumbley, Laura E. (2009), Trends in Global Higher Education: Tracking an Academic Revolution. A Report Prepared for the UNESCO 2009 World Conference on Higher Education. Paris: UNESCO.

Archer, Louise (2008), "The New Neoliberal Subjects? Young/er Academics' Constructions of Professional Identity", Journal of Education Policy, 23(3), 265-285. Belfiore, Eleonora (2004), "Auditing Culture: The Subsidised Cultural Sector in the New Public Managent”, International Journal of Cultural Policy, 10(2), 183-202. Costa, Rosário Couto (2016), "A desvalorização das Humanidades. Universidade, transformações sociais e neoliberalismo”. Tese de Doutoramento, ISCTE-IUL - Instituto Universitário de Lisboa, Lisboa, Portugal.

Deem, Rosemary; Brehony, Kevin J. (2005), "Management as Ideology: The Case of 'New Managerialism' in Higher Education”, Oxford Review of Education, 31(2), 217-235. Etzkowitz, Henry (1993), "Enterprises from Science: The Origins of Science-Based Regional Economic Development", Minerva, 31(3), 326-360.

Etzkowitz, Henry (2001), "The Second Academic Revolution and the Rise of Entrepreneurial Science”, IEEE Technology and Society Magazine, 20(2), 18-29.

Etzkowitz, Henry; Leydesdorff, Loet (2000), "The Dynamics of Innovation: From National Systems and 'Mode 2' to a Triple Helix of University-Industry-Government Relations", Research Policy, 29, 109-123.

Etzkowitz, Henry; Webster, Andrew; Gebhardt, Christiane; Terra, Branca Regina Cantisano (2000), "The Future of the University and the University of the Future: Evolution of Ivory Tower to Entrepreneurial Paradigm”, Research Policy, 29(2), 313-330.

Gewirtz, Sharon; Cribb, Alan (2013), "Representing 30 Years of Higher Education Change: UK Universities and the Times Higher", Journal of Educational Administration and History, 45(1), 58-83.

Gibbons, Michael (1998), Higher Education Relevance in the $21^{\text {st }}$ Century. Washington, D.C.: World Bank.

Giddens, Anthony (2000), As consequências da modernidade. Oeiras: Celta. Tradução de Fernando Luís Machado e Maria Manuela Rocha.

Godin, Benoit (2005), "The Linear Model of Innovation: The Historical Construction of an Analytical Framework", Working Paper no. 30, Project on the History and Sociology of S\&T Statistics. Montreal: Institut National de la Recherche Scientifique. Godin, Benoît (2007), "National Innovation System: The System Approach in Historical Perspective", Working Paper no. 36, Project on the History and Sociology of STI Statistics. Montreal: Institut National de la Recherche Scientifique. 
Godin, Benoît (2014a), "Innovation and Science: When Science Had Nothing to Do with Innovation and Vice-Versa", Working Paper no. 16, Project on the Intellectual History of Innovation. Montreal: Institut National de la Recherche Scientifique.

Godin, Benoît (2014b), “Innovation: un slogan, rien qu'un slogan!”, Millenaire, 3, 1-2.

Godin, Benoît; Gingras, Yves (2000), "The Place of Universities in the System of Knowledge Production”, Research Policy, 29(2), 273-278.

Guerra, J. P. Miller; Nunes, Adérito Sedas (1969), “A crise da Universidade em Portugal: reflexões e sugestões”, Análise Social, VII(25/26), 5-49.

Johnstone, Donald Bruce; Arora, Alka; Experton, William (1998), The Financing and Management of Higher Education. A Status Report on Worldwide Reforms. Washington, D.C.: World Bank.

Lynch, Kathleen (2006), "Neo-Liberalism and Marketisation: The Implications for Higher Education”, European Educational Research Journal, 5(1), 1-17.

Morey, Ann (1992), "Faculty and Students: Teaching, Learning, and Research", in Burton R. Clark; Guy R. Neave (orgs.), The Encyclopedia of Higher Education. Oxford: Pergamon Press.

Nussbaum, Martha C. (2010), Not for Profit. Why Democracy Needs the Humanities. Princeton/Oxford: Princeton University Press.

Olssen, Mark; Peters, Michael A. (2005), "Neoliberalism, Higher Education and the Knowledge Economy: From the Free Market to Knowledge Capitalism", Journal of Education Policy, 20(3), 313-345.

Rhoades, Gary; Slaughter, Sheila (2004), "Academic Capitalism in the New Economy: Challenges and Choices", American Academic, 1(1), 37-60.

Santos, Boaventura de Sousa (2008), "A Universidade do século XXI: para uma reforma democrática e emancipatória da Universidade”, in Boaventura de Sousa Santos; Naomar de Almeida Filho, A Universidade no século XxI. Para uma Universidade Nova. Coimbra: CES/Almedina, 15-78.

Triple Helix Research Group (s.d.), “The Triple Helix Concept”. Consultado a 27.09.2015, em http://triplehelix.stanford.edu/3helix_concept.

Weiler, Hans N. (2006), "Challenging the Orthodoxies of Knowledge: Epistemological, Structural, and Political Implications for Higher Education”, in Guy Neave (org.), Knowledge, Power and Dissent. Critical Perspectives on Higher Education and Research in Knowledge Society. Paris: UNESCO, 61-87.

Wolfe, David A. (2005), “The Role of Universities in Regional Development and Cluster Formation”, in Glen A. Jones; Patricia L. McCarney; Michael L. Skolnik (orgs.), Creating Knowledge, Strengthening Nations. The Changing Role of Higher Education. Toronto: University of Toronto, 167-194.

World Economic Forum (2017), “The Global Risks Report 2017”. Geneva: World Economic Forum. 
Artigo recebido a 22.01.2017

Aprovado para publicação a 22.02.2018

\section{Rosário Couto Costa}

Centro de Investigação e Estudos de Sociologia (CIES-IUL), Instituto Universitário de Lisboa (ISCTE-IUL)

Avenida das Forças Armadas, 1649-026 Lisboa, Portugal

Contacto: mdrss1@iscte-iul.pt

\section{The Ideological Footprint on the Narrative of the Second Academic Revolution. A Critical Analysis of the Construction of a Paradigm}

This article presents a critical review of the second academic revolution. The goal is to show how this milestone is susceptible to different reconstitutions and interpretations, which are not ideologically neutral. For this purpose, a hermeneutic and comparative analysis of texts that theorize this paradigm shift is presented. Four articles by Henry Etzkowitz are taken as the starting point. The vision that these transmit is assumed as the "official" narrative that will have had an influence on the university's most recent transformation. However, when this theorization is confronted with other ideas - be they Etzkowitz's own or those from a study bearing the seal of UNESCO - some inconsistences and limitations emerge as a result.

Keywords: economic development; innovation; neoliberalism; second academic revolution; university.

\section{La trace idéologique dans la narrative de la seconde révolution académique. Analyse critique de la construction d'un paradigme}

Dans cet article, nous procédons à une révision critique de la seconde révolution académique. Le but est de démontrer combien ce jalon est passible de reconstitutions et d'interprétations différentes, qui ne sont pas neutres idéologiquement. Pour ce faire, nous présentons une analyse herméneutique et comparative de textes qui théorisent ce changement de paradigme. Nous prenons pour point de départ quatre articles d'Henry Etzkowitz. Le point de vue qui en est extrait est assumé comme la narrative "officielle" ayant eu une influence sur l'évolution la plus récente de l'université. Cependant, lorsque cette théorisation est confrontée à d'autres idées - que ce soit celles d'Etzkowitz lui-même ou d'une étude portant le sceau de l'UNESCO -, quelques incohérences et limitations se font jour.

Mots-clés: deuxième révolution académique; développement économique; innovation; néolibéralisme; université. 
